\title{
Photochemistry with laser radiation in condensed phase using miniaturized photoreactors
}

\author{
Elke Bremus-Köbberling ${ }^{1}$, Arnold Gillner ${ }^{1}$, Frank Avemaria ${ }^{2}$, Céline Réthoré ${ }^{2}$ \\ and Stefan Bräse ${ }^{*} 2,3$
}

\section{Full Research Paper}

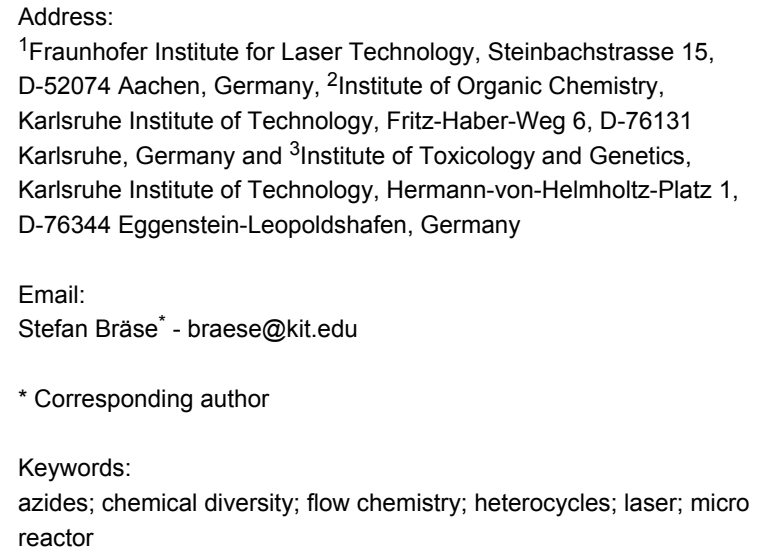

${ }^{1}$ Fraunhofer Institute for Laser Technology, Steinbachstrasse 15, D-52074 Aachen, Germany, ${ }^{2}$ Institute of Organic Chemistry, Karlsruhe Institute of Technology, Fritz-Haber-Weg 6, D-76131 Karlsruhe, Germany and ${ }^{3}$ Institute of Toxicology and Genetics, Karlsruhe Institute of Technology, Hermann-von-Helmholtz-Platz 1, D-76344 Eggenstein-Leopoldshafen, Germany

\section{Email:}

Stefan Bräse* - braese@kit.edu

* Corresponding author

\section{Keywords:}

azides; chemical diversity; flow chemistry; heterocycles; laser; micro reactor

\author{
Beilstein J. Org. Chem. 2012, 8, 1213-1218. \\ doi:10.3762/bjoc. 8.135
}

Received: 31 March 2012

Accepted: 18 June 2012

Published: 31 July 2012

This article is part of the Thematic Series "Recent developments in chemical diversity".

Guest Editor: J. A. Porco Jr.

(C) 2012 Bremus-Köbberling et al; licensee Beilstein-Institut.

License and terms: see end of document.

\begin{abstract} high efficiency.

\section{Introduction}

Classical combinatorial chemistry [1,2] approaches usually aim at the synthesis of multi-milligram amounts of new compounds to extend screening decks used in multiple screening campaigns [3]. An alternative method enabled by the maturing microreaction technology and the use of flow chemistry [4-6] is the integration of synthesis and screening in one integrated lab-on-achip approach [7].
\end{abstract}

Miniaturized microreactors enable photochemistry with laser irradiation in flow mode to convert azidobiphenyl into carbazole with

Using this methodology we have integrated photochemistry in a miniaturized reaction setup to enable combinatorial flow chemistry in lab-on-a-chip applications.
Photochemical processes are in this case particularly interesting because of their enhanced molecular activation [8]. Photochemistry in microreactors is an emerging research area [9], and especially photocatalytic reactions have been investigated in detail by Matsushita et al. [10,11]. To date there are a couple of reported examples combining miniaturized reaction systems with synthetic laser photochemistry [5,6,9,12-28].

The influence of photons, which are delivered via a suitable light-transparent window, on the processes running in miniaturized photoreactors, is investigated with a focus on increasing 
the yield and selectivity as well as decreasing the reaction time. Photochemistry with laser radiation is a promising tool to broaden the application spectrum of miniaturized systems, by facilitating a powerful activation step due to a wide range of available wavelengths and energy ranges [29,30]. Moreover, the optical systems can be designed in a way that the reaction initiation by photons and an additional online analysis of the running reaction is feasible.

\section{Results and Discussion Design and fabrication}

In order to realize photochemical synthesis, several reactors and small reactor arrays with reaction volumes of approximately $1 \mathrm{~mL}$ down to $35 \mu \mathrm{L}$ were developed. These reactors were especially designed for the stimulation of photochemical reactions (UV-vis radiation) as well as for demanding reaction conditions, such as the rapid elevation of temperature (with pulsed IR-laser radiation) or pressure pulses (due to the evaporation of the solvent upon the introduction of energy).

Several microstructured reactor types were designed and produced for reactions in the liquid phase. They are equipped with quartz-glass cover plates, transparent to the laser radiation, pressed onto an appropriate sealing material. Moreover, channels suitable for the mixing and reaction of two or more isopycnic solutions were built in a polymer bloc by mechanical treatment [31]. The provision of bubble-free fluid is ensured in this case by microchannels in at least two levels, which are built from corresponding structured layers. These reactors were made of polyether ether ketone (PEEK) and polytetrafluoroethylene (PTFE) [32] to study the influence of side reactions with the reactor material, which could reduce the yield of the desired reaction product. The multilayer system is placed in a stainlesssteel frame.

With this type of reactor, it is possible to realize a series of reactions in parallel by arranging the reactor chambers in an $(\mathrm{n} \times \mathrm{m})$ matrix. The microreactors applied for this study have four reaction chambers with varying volumes of the chambers due to increasing depth, and different connections for the reagent entrance (Figure 1).
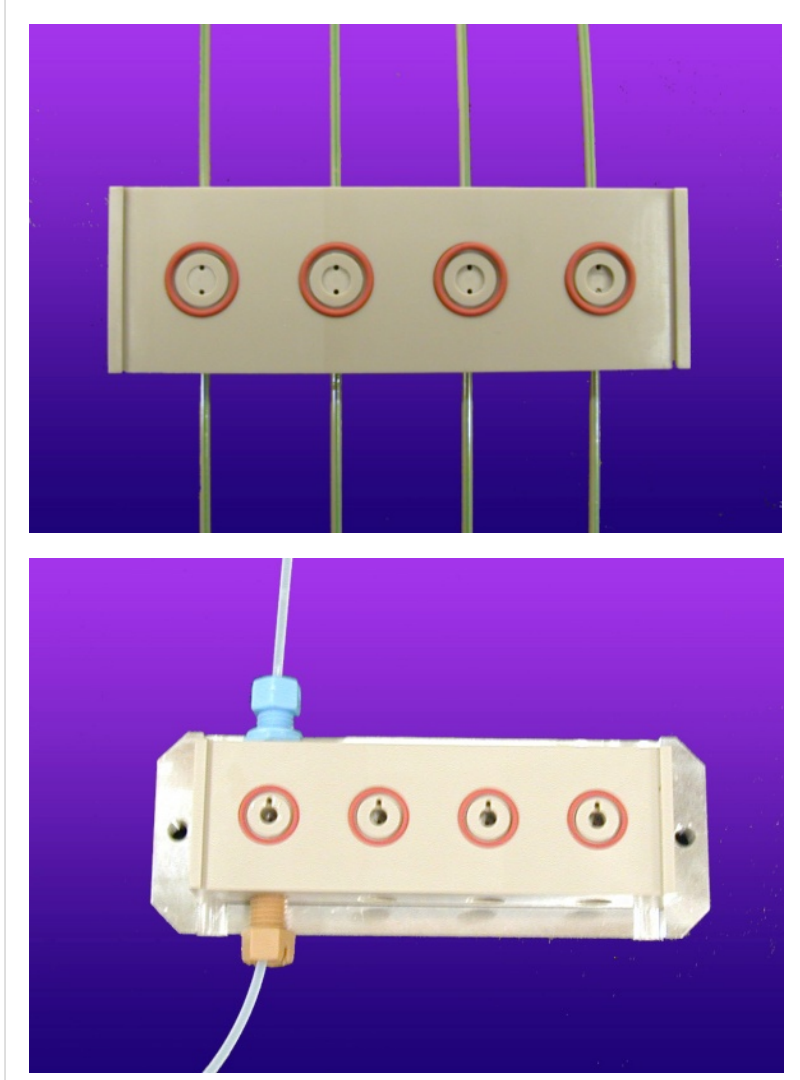

Figure 1: Four-fold PEEK-reactors with increasing chamber depths from left to right and different techniques of fluid connection; top: glued PEEK-capillaries, bottom: $1 / 4$ in. screw connections.

\section{Photochemistry}

The combinatorial synthesis of heterocycles and among them of carbazole is of particular interest since they are potential active pharmaceutical compounds [33-35]. The photolysis of 2-azidobiphenyl (1) with the help of a conventional UV-lamp has been used for the synthesis of carbazole (2) since 1960 (Scheme 1) [36-39].<smiles>[R4][X]#[X]</smiles>

1

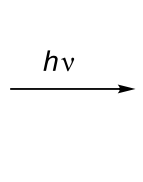<smiles>c1ccc2c(c1)[nH]c1ccccc12</smiles>

2

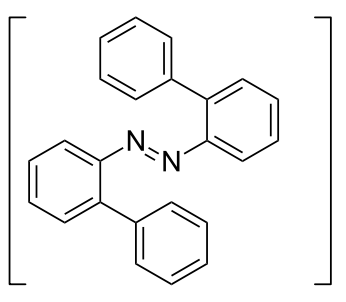

side product

Scheme 1: Synthesis of carbazole (2) by photolysis. 
However, there are only a few examples of substituted products obtained by this reaction, and several side-products, such as the corresponding azo-derivatives, are usually formed [36,40-44] During the past few years, we successfully employed triazene resins, such as $\mathbf{4}$, which are readily available from aniline in the synthesis of a library of aromatic derivatives [45-48]. Moreover, triazene-resins are perfectly suitable for the synthesis of arylazides 5 (Scheme 2) [49].<smiles>[R]c1ccccc1/N=N/N(Cc1ccccc1)Cc1ccccc1</smiles>

4

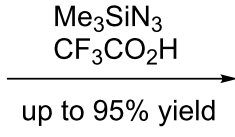

5
Scheme 2: Synthesis of arylazides 2 by solid-phase synthesis.

The photochemical decomposition of arylazides into carbazoles is appropriate for application in miniaturized photoreactors, since significant results can be observed by an online analysis through HPLC and GC [50]. Because of the miniaturization, online analysis is especially suitable for our setup.

We therefore investigated whether the photoreaction can be realized in miniaturized photoreactors and to what extent the use of a laser as a photon source is advantageous. The irradiation of 2-azidobiphenyl (1) in methanol with a conventional xenon lamp ( $400 \mathrm{~W}, \lambda>345 \mathrm{~nm}$ ) required $18 \mathrm{~h}$ for $50 \%$ yield ( $95 \%$ selectivity) in a $10 \mathrm{~mm}$ cell with an $8 \mathrm{~mm}$ light-exposure diameter (Figure 2).

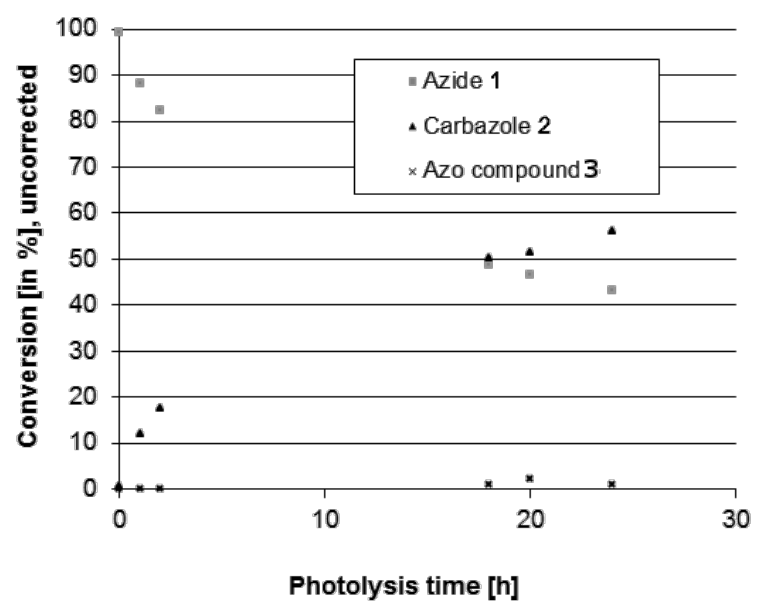

Figure 2: Photolysis results in batch setup (flask) with a xenon lamp $(400 \mathrm{~W}, \lambda>345 \mathrm{~nm})$
Frequency-tripled Nd:YAG laser radiation $(\lambda=355 \mathrm{~nm}, 8 \mathrm{kHz}$ pulse frequency; pulse duration $26 \mathrm{~ns}$ ) was chosen because the wavelength is close to that of the applied UV-lamp, $355 \mathrm{~nm}$ is usually within the absorption area of azides, and this laser type is commonly used in most laser labs. We applied a single-pulse power of 0.16 to $3 \mathrm{~W}$ resulting in pulse energies between 4 and $87 \mathrm{~nJ}$ and energy densities of approximately 0.02 to $0.17 \mu \mathrm{J} / \mathrm{cm}^{2}$ within a defocused laser spot of 0.2 to $0.5 \mathrm{~cm}^{2}$, to carry out the same reaction (Scheme 1), but carbazole was obtained much faster from 2-azidobiphenyl (1). Compared to conventional UV sources, the use of laser irradiation clearly accelerated the reaction: from $18 \mathrm{~h}$ (Xe lamp, Figure 2) to $30 \mathrm{~s}$ (Nd:YAG laser) for 50\% yield and 95\% selectivity, calculated from the data presented in Figure 3. This reaction was successfully carried out in a miniaturized photoreactor (Figures 3-6).

The monomolecular reaction can be realized by using laser radiation of $355 \mathrm{~nm}$ wavelength as a photon source, in a clean way, avoiding almost completely the formation of the undesired

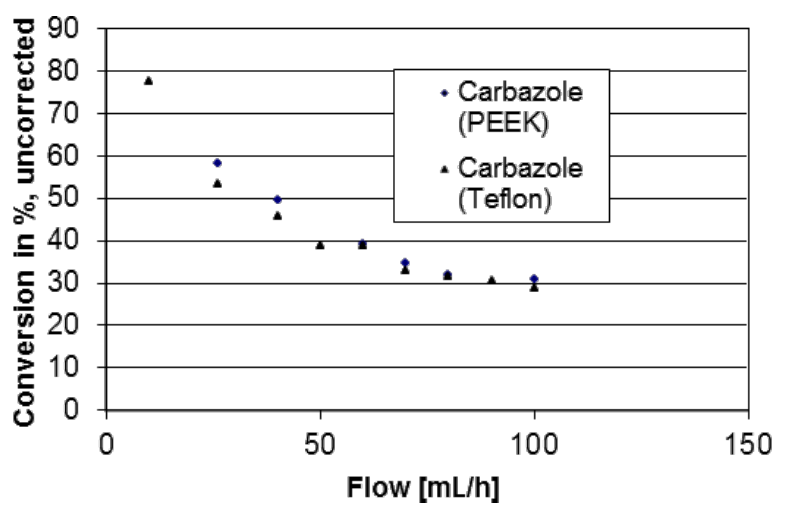

Figure 3: Carbazole synthesis in miniaturized photoreactors Type II (PEEK and Teflon), flow control, $\mathrm{P}=0.92 \mathrm{~W}$.

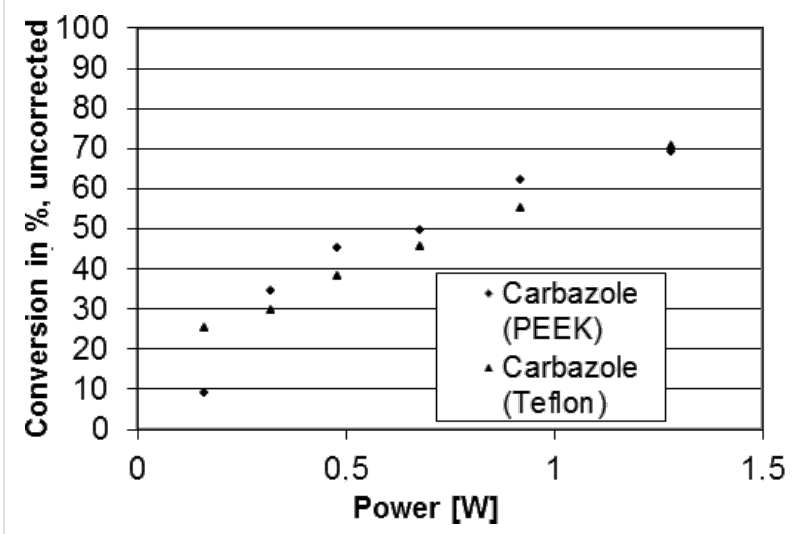

Figure 4: Carbazole synthesis in miniaturized photoreactors Type II (PEEK and Teflon), power control, flow $26 \mathrm{~mL} / \mathrm{h}$. 


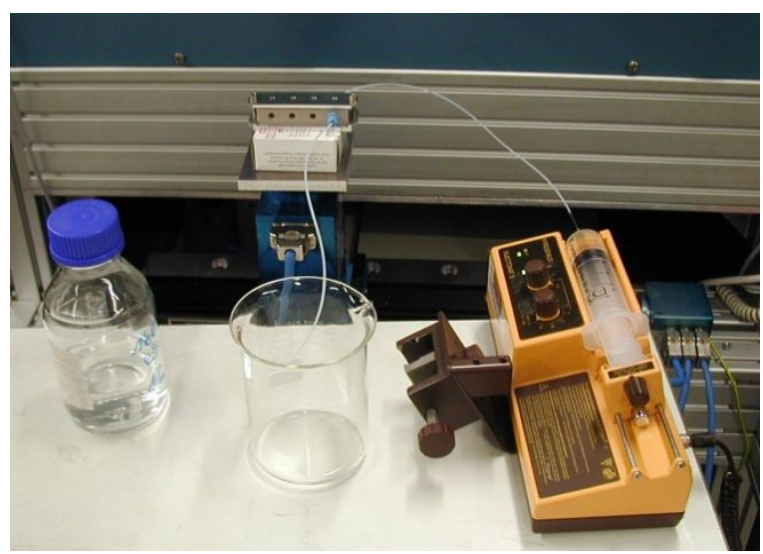

Figure 5: Test setup with continuously operating, miniaturized photoreactor.

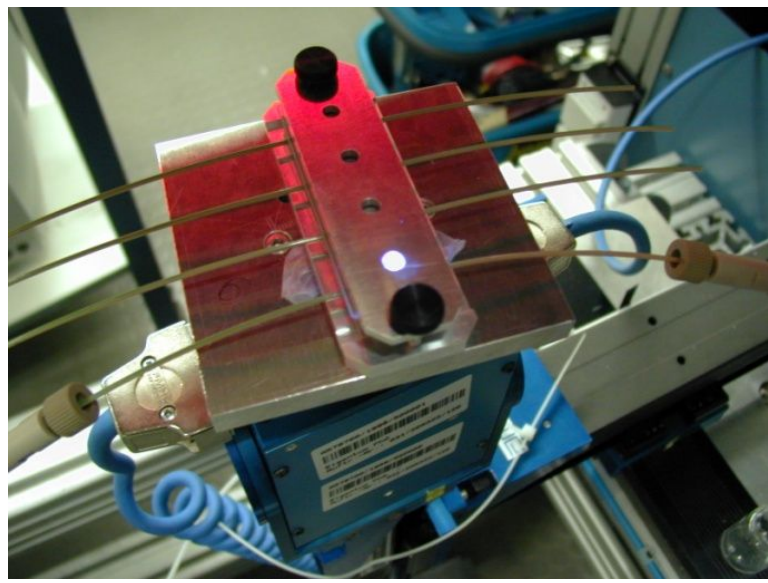

Figure 6: The miniaturized photoreactor (PEEK) during photolysis.

diazo derivatives 3 . The side reaction is supposedly reduced due to a lesser effect of heating owing to the small bandwidth irradiation and minimized exposure time through the miniaturized flow setup.

During these tests, it was shown that a largely better selectivity can be achieved, compared to the one obtained in a standard UV irradiation setup (Figure 2). Experiments were performed in batch as well as flow-injection configuration. The continuous process used allowed us to vary the residence time in the reactor by regulating the flow speed of the reactant solution, with the help of a syringe pump (Figure 5).

For this study, reactors made of PEEK, as well as PTFE reactors were used, leading to similar yields of carbazole (Figure 3 and Figure 4), showing no major influence of the reactor material on the reaction.
The deviations from linearity in the low power area of Figure 4 can be attributed to fluctuations of the laser power. For the high-power area, a correlation between yield, power and reaction time, which can be explained by kinetics, is observed.

\section{Conclusion}

The preparation and application of polymeric, miniaturized photoreactors, equipped for the effective use of photons in the reaction chamber, provided by frequency-converted laser sources, was successfully shown.

With these reactors or reactor components, the photonic influence on reactions in miniaturized photoreactors was proven to be useful in parameter studies in which laser power and flow rate were varied.

The advantages of laser chemistry in the condensed phase compared to standard photochemical approaches have been shown in this preliminary study, proving the suitability of laser photochemistry for organic synthesis. Thanks to the further miniaturization and the availability of new moderately priced laser systems even better suited beam sources can be provided for photochemistry.

In the described experiments, laser radiation of $355 \mathrm{~nm}$ wavelength (frequency-tripled Nd:YAG) was used. Since the spectral range of interest for most photoreactions ranges from the ultraviolet to the visible region, tunable laser systems (optical parametric oscillators) feature promising properties for use photochemical experiments. Thus, the irradiation wavelength can be adapted to the needs of the reaction (e.g., to a shifted absorption maximum of the reactant due to substitution) facilitating a large range of applications of this technique. Furthermore, IR laser sources (diode laser, Nd:YAG laser, $\mathrm{CO}_{2}$ laser) could be applied for pulsed temperature and pressure elevation in microreactors, as well as microwave stimulation to accelerate reactions.

\section{Experimental}

All starting materials and products were characterized by standard techniques ( ${ }^{1} \mathrm{H} \mathrm{NMR},{ }^{13} \mathrm{C} \mathrm{NMR}$, and elemental analysis) and are compared with authentic samples. The products were analyzed by GC-MS (internal standard, dodecane) and/or HPLC.

A solution of 2-azidobiphenyl (1) was continuously added to a miniaturized reactor of type II (see Figure 1, dimension of the reactor chamber $3 \times 5 \mathrm{~mm}, 35 \mu \mathrm{L}$ volume) with a syringe pump. The chamber was continuously irradiated with a Nd:YAG laser $(355 \mathrm{~nm})$. At a constant flow of $26 \mathrm{~mL} / \mathrm{h}$, the laser-pulse power was varied from 0.16 to $1.28 \mathrm{~W}$. Furthermore, at a constant 
intermediate power of $0.92 \mathrm{~W}$ the flow rate $(10$ to $100 \mathrm{~mL} / \mathrm{h})$ and therefore the dwell time (exposure time) in the reactor was varied. The yield was determined by HPLC.

\section{Supporting Information}

\section{Supporting Information File 1}

Description of the flow reactor setup, kinetics, experimental procedures and spectroscopic data of all compounds. [http://www.beilstein-journals.org/bjoc/content/ supplementary/1860-5397-8-135-S1.pdf]

\section{Acknowledgements}

We thank the Fonds der Chemischen Industrie for financial support.

\section{References}

1. Nicolaou, K. C.; Hanko, R.; Hartwig, W., Eds. Handbook of Combinatorial Chemistry; VCH: Weinheim, Germany, 2002.

2. Ehrfeld, W.; Hessel, V.; Löwe, H. Microreactors - New Technology for Modern Chemistry; Wiley-VCH: Weinheim, Germany, 2000.

3. Chen, I.-J.; Hubbard, R. E. J. Comput.-Aided Mol. Des. 2009, 23, 603-620. doi:10.1007/s10822-009-9280-5

4. Ley, S. V.; Baxendale, I. R. Chimia 2008, 62, 162-168. doi:10.2533/chimia.2008.162

5. Wirth, T., Ed. Microreactors in Organic Synthesis and Catalysis; Wiley-VCH: Weinheim, Germany, 2008.

6. Yoshida, J.-i., Ed. Flash Chemistry: Fast Organic Synthesis in Microsystems; John Wiley \& Sons: Chichester, U.K., 2008.

7. Bapna, A.; Vickerstaffe, E.; Warrington, B. H.; Ladlow, M.; Fan, T.-P. D.; Ley, S. V. Org. Biomol. Chem. 2004, 2, 611-620. doi:10.1039/b313414h

8. McNaught, A. D.; Wilkinson, A. IUPAC. Compendium of Chemical Terminology, 2nd ed.; Blackwell Scientific Publications: Oxford, U.K., 1997.

9. Coyle, E. E.; Oelgemöller, M. Photochem. Photobiol. Sci. 2008, 7, 1313-1322. doi:10.1039/b808778d

10. Matsushita, Y.; Iwasawa, M.; Suzuki, T.; Ichimura, T. Chem. Lett. 2009, 38, 846-847. doi:10.1246/cl.2009.846

11. Matsushita, Y.; Ohba, N.; Suzuki, T.; Ichimura, T. Catal. Today 2008, 132, 153-158. doi:10.1016/j.cattod.2007.12.078

12. The preliminary work has been submitted as patent: Bremus, E.; Gillner, A.; Bräse, S.; Köbberling, J. PCT Int. Appl. (2000), WO 2000062929 A2 20001026. Language: German, Database: CAPLUS and described in [36]. The reactor and the photochemistry of azides have also been the subject of various public presentations since 2002 without the details being disclosed.

13. Kirschning, A. Beilstein J. Org. Chem. 2011, 7, 1046-1047. doi:10.3762/bjoc.7.119

See also the Thematic Series "Chemistry in flow systems II".

14. Oelgemöller, M.; Shvydkiv, O. Molecules 2011, 16, 7522-7550. doi:10.3390/molecules 16097522 See for a recent review.

15. Davis, R. H.; Palmer, D. D. Apparatus and method for performing photochemical reactions. WO Patent WO2005123241, Dec 29, 2005.
16. For a commercial photo-microreactor see:

http://www.ymc-europe.com/ymceurope/products/flow-chemistry/flow-c hemistry-start.html\#keychemlumino

17. Nindl, G.; Hess, W.; Waite, L. R.; Balcavage, W. X. Biomed. Sci. Instrum. 2005, 41, 187-192.

18. Peterson, D. S.; Rohr, T.; Svec, F.; Fréchet, J. M. J. Anal. Chem. 2003, 75, 5328-5335. doi:10.1021/ac034108j

19. Ouchi, A.; Sakai, H.; Oishi, T.; Kaneda, M.; Suzuki, T.; Saruwatari, A.; Obata, T. J. Photochem. Photobiol., A 2008, 199, 261-266. doi:10.1016/j.jphotochem.2008.05.024

20. Bourne, R. A.; Han, X.; Poliakoff, M.; George, M. W. Angew. Chem., Int. Ed. 2009, 48, 5322-5325. doi:10.1002/anie.200901731

21. Lu, H.; Schmidt, M. A.; Jensen, K. F. Lab Chip 2001, 1, 22-28. doi:10.1039/b104037p

22. Goodell, J. R.; McMullen, J. P.; Zaborenko, N.; Maloney, J. R.; Ho, C.-X.; Jensen, K. F.; Porco, J. A., Jr.; Beeler, A. B. J. Org. Chem. 2009, 74, 6169-6180. doi:10.1021/jo901073v

23. Pimparkar, K.; Yen, B.; Goodell, J. R.; Martin, V. I.; Lee, W.-H.; Porco, J. A., Jr.; Beeler, A. B.; Jensen, K. F. J. Flow Chem. 2011, 1, 53-55. doi:10.1556/jfchem.2011.00006

24. Tucker, J. W.; Zhang, Y.; Jamison, T. F.; Stephenson, C. R. J. Angew. Chem., Int. Ed. 2012, 51, 4144-4147. doi:10.1002/anie.201200961

25. Vasudevan, A.; Villamil, C.; Trumbull, J.; Olson, J.; Sutherland, D.; Pan, J.; Djuric, S. Tetrahedron Lett. 2010, 51, 4007-4009. doi:10.1016/j.tetlet.2010.05.119

26. Fuse, S.; Tanabe, N.; Yoshida, M.; Yoshida, H.; Doi, T.; Takahashi, T. Chem. Commun. 2010, 46, 8722-8724. doi:10.1039/c0cc02239j

27. Mimieux Vaske, Y. S.; Mahoney, M. E.; Konopelski, J. P.; Rogow, D. L.; McDonald, W. J. J. Am. Chem. Soc. 2010, 132, 11379-11385. doi:10.1021/ja1050023

28. Wegner, J.; Ceylan, S.; Kirschning, A. Chem. Commun. 2011, 47, 4583-4592. doi:10.1039/c0cc05060a

29. Davies, D. M. E.; Murray, C.; Berry, M.; Orr-Ewing, A. J.; Booker-Milburn, K. I. J. Org. Chem. 2007, 72, 1449-1457. doi:10.1021/jo062316g

30. Hara, M.; Tojo, S.; Majima, T. J. Phys. Chem. A 2003, 107, 4778-4783. doi:10.1021/jp027002I

31. Nagy, K. D.; Shen, B.; Jamison, T. F.; Jensen, K. F. Org. Process Res. Dev. 2012, 16, 976-981. doi:10.1021/op200349f

32. Peterson, T. P.; Polyzos, A.; O’Brien, M.; Ulven, T.; Baxendale, I. R.; Ley, S. V. ChemSusChem 2012, 5, 274-277.

33. Bräse, S.; Banert, K. Organic Azides - Syntheses and Applications; Wiley: Chichester, U.K., 2009.

See for the use of azides in heterocycle chemistry.

34. Stokes, B. J.; Jovanović, B.; Dong, H.; Richert, K. J.; Riell, R. D.; Driver, T. G. J. Org. Chem. 2009, 74, 3225-3228. doi:10.1021/jo9002536 And references cited therein.

35. Jordan-Hore, J. A.; Johansson, C. C. C.; Gulias, M.; Beck, E. M.; Gaunt, M. J. J. Am. Chem. Soc. 2008, 130, 16184-16186. doi:10.1021/ja806543s

36. Bräse, S.; Gil, C.; Knepper, K.; Zimmermann, V. Angew. Chem. 2005, 117, 5320-5374. doi:10.1002/ange.200400657 Angew. Chem., Int. Ed. 2005, 44, 5188-5240. doi:10.1002/anie.200400657 See for reactions and safety issues of azides.

37. Swenton, J. S.; Ikeler, T. J.; Williams, B. H. J. Am. Chem. Soc. 1970, 92, 3103-3109. doi:10.1021/ja00713a031 
38. Sundberg, R. J.; Heintzelman, R. W. J. Org. Chem. 1974, 39, 2546-2552. doi:10.1021/jo00931a020

39. Sundberg, R. J.; Gillespie, D. W.; DeGraff, B. A. J. Am. Chem. Soc. 1975, 97, 6193-6196. doi:10.1021/ja00854a042

40. Platz, M. S. Acc. Chem. Res. 1995, 28, 487-492. doi:10.1021/ar00060a004

41. Meth-Cohn, O. Heterocycles 1980, 14, 1497-1516. doi:10.3987/R-1980-10-1497

42. Hawkins, D. G.; Meth-Cohn, O. J. Chem. Res., Miniprint 1982, 1218-1225.

43. Albini, A.; Bettinetti, G.; Minoli, G. J. Chem. Soc., Perkin Trans. 2 1999, 2803-2807. doi:10.1039/a903863i

44. Forbes, E. J.; Tatlow, J. C.; Wragg, R. T. Tetrahedron 1960, 8, 73-78.

45. Bräse, S. Acc. Chem. Res. 2004, 37, 805-816. doi:10.1021/ar0200145

46. Bräse, S.; Enders, D.; Köbberling, J.; Avemaria, F. Angew. Chem.

1998, 110, 3614-3616.

doi:10.1002/(SICI)1521-3757(19981217)110:24<3614::AID-ANGE3614 >3.0.CO;2-R

Angew. Chem., Int. Ed. 1998, 37, 3413-3415.

doi:10.1002/(SICI)1521-3773(19981231)37:24<3413::AID-ANIE3413>3 .0.CO;2-K

47. Bräse, S.; Schroen, M. Angew. Chem. 1999, 111, 1139-1142. doi:10.1002/(SICI)1521-3757(19990419)111:8<1139::AID-ANGE1139> 3.0.CO;2-F

Angew. Chem., Int. Ed. 1999, 38, 1071-1073. doi:10.1002/(SICI)1521-3773(19990419)38:8<1071::AID-ANIE1071>3. $0 . C O ; 2-9$

48. Hafner, A.; Bräse, S. Angew. Chem. 2012, 124, 3773-3775. doi:10.1002/ange.201107414

49. Avemaria, F.; Zimmermann, V.; Bräse, S. Synlett 2004, 1163-1166. doi:10.1055/s-2004-82298

50. Bou-Hamdan, F. R.; Lévesque, F.; O'Brien, A. G.; Seeberger, P. H. Beilstein J. Org. Chem. 2011, 7, 1124-1129. doi:10.3762/bjoc.7.129 See for a related work leading to azepinones.

\section{License and Terms}

This is an Open Access article under the terms of the Creative Commons Attribution License (http://creativecommons.org/licenses/by/2.0), which permits unrestricted use, distribution, and reproduction in any medium, provided the original work is properly cited.

The license is subject to the Beilstein Journal of Organic Chemistry terms and conditions:

(http://www.beilstein-journals.org/bjoc)

The definitive version of this article is the electronic one which can be found at: $\underline{\text { doi: } 10.3762 / \text { bjoc. } 8.135}$ 